\title{
Sinhala translation of the Perinatal Anxiety Screening Scale: a valid and reliable tool to detect anxiety disorders among antenatal women
}

\author{
M. N. Priyadarshanie ${ }^{1 *}$, M. D. I. A. Waas ${ }^{2}$, C. S. E. Goonewardena ${ }^{3}$, A. Balasuriya ${ }^{4}$, B. C. V. Senaratna ${ }^{3,5+}$ and \\ D. M. S. Fernando ${ }^{6+}$
}

\begin{abstract}
Background: Anxiety disorders during pregnancy are not routinely assessed in Sri Lanka despite being common and being associated with adverse pregnancy outcomes. Screening can facilitate early detection and management of anxiety and improve pregnancy outcomes. Our aim was to determine the validity of the Sinhala translation of the Perinatal Anxiety Screening Scale (PASS) to detect anxiety among Sri Lankan pregnant women.

Methods: A cross-sectional study was conducted in antenatal clinics of a teaching hospital in Colombo District. The PASS was translated to Sinhala using the standard translation/ back-translation method. Pregnant women $(n=221)$ were sequentially recruited and assessed by a psychiatrist until 81 women with anxiety disorder were diagnosed using the International Classification of Diseases-10 criteria (gold standard). The Sinhala translation of the PASS (PASS-S) was administered to all recruited women, including 140 women without anxiety. Receiver-OperatingCharacteristic (ROC) analysis was performed, the optimal cut-off score for PASS-S was determined, and its validity was assessed using sensitivity, specificity, predictive values and positive and negative likelihood ratios. Internal consistency was assessed using Cronbach's alpha. Test-retest and inter-rater reliability for PASS-S score and anxiety classification were assessed using intra class correlation coefficient (ICC) and Cohen's kappa (k), respectively.

(Continued on next page)
\end{abstract}

\footnotetext{
*Correspondence: nirmalap@kdu.ac.lk; nirmala_ahs@yahoo.com

${ }^{\dagger}$ Senaratna BCV and Fernando DMS are equal senior authors.

${ }^{1}$ Department of Nursing \& Midwifery, Faculty of Allied Health Sciences, Kotelawala Defence University, Rathmalana, Sri Lanka

Full list of author information is available at the end of the article
}

(c) The Author(s). 2020 Open Access This article is licensed under a Creative Commons Attribution 4.0 International License, which permits use, sharing, adaptation, distribution and reproduction in any medium or format, as long as you give appropriate credit to the original author(s) and the source, provide a link to the Creative Commons licence, and indicate if changes were made. The images or other third party material in this article are included in the article's Creative Commons licence, unless indicated otherwise in a credit line to the material. If material is not included in the article's Creative Commons licence and your intended use is not permitted by statutory regulation or exceeds the permitted use, you will need to obtain permission directly from the copyright holder. To view a copy of this licence, visit http://creativecommons.org/licenses/by/4.0/. The Creative Commons Public Domain Dedication waiver (http://creativecommons.org/publicdomain/zero/1.0/) applies to the data made available in this article, unless otherwise stated in a credit line to the data. 
(Continued from previous page)

Results: The mean age ( \pm SD) of women was 30( \pm 5.8$)$ years, and 53.7\% were multiparous. A psychiatrist diagnosed anxiety disorder was made in $37.0 \%$ of women, while the PASS-S, at its optimal cut-off of $\geq 20$, classified $37.5 \%$ of women as having anxiety disorders. The area under the ROC curve for the PASS-S was $0.96(95 \% \mathrm{Cl} 0.94-0.99)$. Sensitivity, specificity and positive and negative predictive values of the PASS-S were $0.93(95 \% \mathrm{Cl} 0.84-0.97), 0.90$ (95\% Cl 0.83-0.94), 0.85 (95\% Cl 0.75-0.90) and 0.95 (95\% Cl 0.89-0.98), respectively. Positive and negative likelihood ratios were $8.8(95 \% \mathrm{Cl} 5.3-14.5)$ and $0.08(95 \% \mathrm{Cl} 0.04-0.18)$, respectively, and the internal consistency was high (Cronbach's alpha 0.95). Four-factor structures obtained by exploratory factor analysis were "acute anxiety and adjustment", "social anxiety, specific fears and trauma", "perfectionism and control" and "general anxiety".Test-retest reliability was high for the PASS-S score (ICC 0.85[95\% Cl 0.65-0.96]) and anxiety classification ( $\mathrm{k} 0.77[95 \% \mathrm{Cl} 0.34-$ 1.2]). Inter-interviewer reliability was also high (ICC 0.92[95\% Cl 0.81-0.97] for the PASS-S score and ( $\mathrm{k0.86} \mathrm{[95 \%} \mathrm{Cl}$ 0.59-1.1] for anxiety classification).

Conclusion: The Sinhala translation of the PASS is a valid and reliable instrument to screen for anxiety disorders among antenatal women in Sri Lanka.

Keywords: Perinatal anxiety, Screening, Validation, PASS, Antenatal clinics, Sri Lanka

\section{Background}

Anxiety symptoms are common during pregnancy and the postpartum period [1], which could be due to continuation or worsening of pre-existing anxiety, caused by the physiological and psycho-social changes associated with pregnancy or new onset anxiety; both of which are likely to be higher among perinatal women than in the general population [2-4]. Anxiety during pregnancy may be generalised anxiety or pregnancy-specific anxiety. Pregnancy-specific anxiety is an emotional state resulting from the anticipated uncertainties related to pregnancyspecific issues during antenatal and/or post-partum periods, especially due to worries about labour, wellness of the baby to be born and neonatal care $[5,6]$.

Anxiety during pregnancy in low- and middle-income countries [7] is as high as $25 \%$, compared to $10 \%$ in developed countries [8]. The prevalence of antenatal anxiety and depression is $20 \%$ in Asian women [9] but the prevalence of antenatal anxiety is not known to Sri Lankans. However, antenatal anxiety often coexists with antenatal depression and is a strong predictor of postpartum depression. In Sri Lanka the latter two conditions have high prevalence of $16 \%$ [10] and 27\% [11], respectively, which suggests that undetected antenatal anxiety among Sri Lankan women is likely to be high.

Limited evidence suggests that antenatal anxiety is associated with adverse foetal and maternal outcomes including still birth, intrauterine growth restriction (IUGR), prolonged labour, caesarean deliveries, preterm birth, low birth-weight, and low Apgar scores at birth [5, 12-15]. Early detection and management of antenatal anxiety will improve pregnancy outcomes [16]. The gold standard to detect anxiety is diagnosis by a psychiatrist [17]. However, as it is not feasible for all pregnant women to be routinely assessed by a psychiatrist, standard questionnaires are used to screen pregnant women for anxiety. Some of these questionnaires screen for only general anxiety states (e.g. State-Trait Anxiety Inventory [STAI] [18]) or generalized anxiety disorder (e.g.Generalized Anxiety Disorder 7-item [GAD-7] scale [19]), while others screen for only pregnancy-specific anxiety (e.g.Pregnancy related Anxiety Questionnaire [PrAQ] [20] and Pregnancy Anxiety Scale [21]). Using only the pregnancy-specific anxiety questionnaires, focusing on symptoms such as fears related to pregnancy and child birth, the mother's concerns on her physical appearance and relationship issues within the family, is useful to capture the anxiety related to pregnancy itself, but has limited utility in detecting a broader range of anxiety disorders [22]. Questionnaires that screen for a spectrum of anxiety disorders during pregnancy will be more useful to screen antenatal women, as it is the presence of any anxiety disorder that is likely to cause adverse outcomes, rather than any specific anxiety disorder including anxiety specific to pregnancy.

The Perinatal Anxiety Screening Scale (PASS) is an acceptable, psychometrically-sound questionnaire that has performed well in screening for antenatal and postnatal anxiety disorders [22] including those due to pregnancy. It screens for a broad range of anxiety presentations, and it is not confounded by the physiological symptoms of pregnancy. Being the first tool developed to screen a broad range of anxiety disorders among a perinatal population, originally validated among antenatal and postnatal women, the PASS possesses a valid and reliable case finding ability [22]. It has been utilized in many countries to detect antenatal anxiety disorders [23-26]. Good validity and reliability reported for translations such as the PASS-Turkish version (PASS-TR) [24] and the PASS Bangladesh version (Bangala PASS) [25] suggest that it is robust in cross-cultural adaptation.

In Sri Lanka, the prevalence of adverse pregnancy outcomes remains high despite other maternal health 
indices being satisfactory. This could be due to causes that are not assessed routinely during pregnancy, including anxiety disorders. However, no valid screening tool is available in Sri Lanka to detect antenatal anxiety disorders. Although the Edinburgh Postnatal Depression Scale (EPDS) which screens for postnatal depression has been used [27], this includes only three items to screen for anxiety. Furthermore, these items do not distinguish between anxiety and depression [2]. Therefore, a valid and reliable questionnaire to screen for antenatal anxiety disorder in Sri Lanka is a timely need. Our aim was to translate the PASS into Sinhala language and validate it among pregnant women to address this requirement.

\section{Methods}

\section{Study design and setting}

This was a descriptive cross-sectional study conducted among antenatal women attending hospital antenatal clinics (ANCs). The study was conducted in the ANCs of Colombo South Teaching Hospital (CSTH), which is the second largest tertiary-care institution in Colombo District with a bed strength of 1096 and an annual turnover of 150,000 in-ward patients and 75,000 outpatients. Antenatal women from its catchment area, which is urban/semi-urban, and those referred to it from elsewhere due to risk conditions are registered at ANCs run by three obstetrics units, and they are followed up until the delivery $[28,29]$.

\section{Study population and sampling}

The study population was pregnant women who attend ANCs of CSTH.

Pregnant women attending ANCs at CSTH were recruited to the study irrespective of the trimester of pregnancy (first, second or third trimesters). The inclusion criterion was age of at least 18 years. Those with disabilities such as hearing difficulty, visual and speaking problems were excluded. Although diagnosed but currently untreated mental disorders were also an exclusion criterion, no one was excluded based on this criterion.

As per the expected sensitivity (70\%) and specificity (30\%) of the PASS [22], the calculated sample size was 81 antenatal women with anxiety disorder and 81 women without anxiety disorder.

Eligible pregnant women were recruited using systematic random sampling with a sampling interval of 5 . The sampling frame was the list of registered women in the ANC attendance registry.

\section{Data collection procedure}

Participants were given written information detailing the purpose of the study, voluntary participation, procedures and time required for the procedures, potential benefits, discomforts, confidentiality and the ability to terminate participation at participant's discretion without having to face any adverse consequences. The information was also read out by the Principal Investigator (PI), and queries raised by the participants were clarified. The participants were given an additional $1 \mathrm{~h}$ on the average to ask any further questions. The decision to participate in the study was purely voluntary and written informed consent was taken from all participants. The participants were also given contact details of the research team to enable them to clarify any concerns even after the study participation was over.

The PI, who is a graduate nurse, checked the eligibility for the study based on the selection criteria by directly questioning the participants and checking the antenatal records. Recruited women were assessed by a psychiatrist as described below. Recruitment continued until 81 women with anxiety disorder were diagnosed.

\section{Measures}

\section{Screening test: perinatal anxiety screening scale}

The PASS is a 31-item validated instrument used to screen for anxiety disorders and cover all domains of anxiety in antenatal and postpartum women [22]. Each item enquires about the presence of anxiety symptoms during the preceding 1 month and is scored on a Likert scale ranging from 0 (not at all) to 3 (almost always). A total score between 0 and 20 is considered as "asymptomatic", 21-41 as "mild-moderate anxiety symptoms" and 42-93 as "severe anxiety symptoms". An overall score higher than 26 indicates a high risk of presenting with anxiety disorders [22].

\section{Reference test: diagnostic interview using International Classification of Diseases-10}

The International Classification of Diseases and Related Health Problems (ICD-10) provides clinical descriptions and diagnostic guidelines of diseases. It also provides the inclusion and exclusion criteria for diagnoses, allowing a degree of flexibility to be retained for diagnostic decisions in clinical setting [30]. Diagnostic interview by a psychiatrist, as per ICD-10 criteria, is the gold standard of diagnosis of anxiety disorder.

The present study was conducted in three phases. Firstly, the PASS was translated into Sinhala and its content, conceptual and semantic validity were assessed. Secondly, the construct validity of the Sinhala translation was examined. Thirdly, the criterion validity and reliability of the Sinhala translation was determined.

\section{Translation of PASS into Sinhala language}

Translation and adaptation was carried out according to the World Health Organization (WHO) guidelines on the process of translation and adaptation of instruments [31]. Stages of translation of PASS (Fig. 1) are given below. 


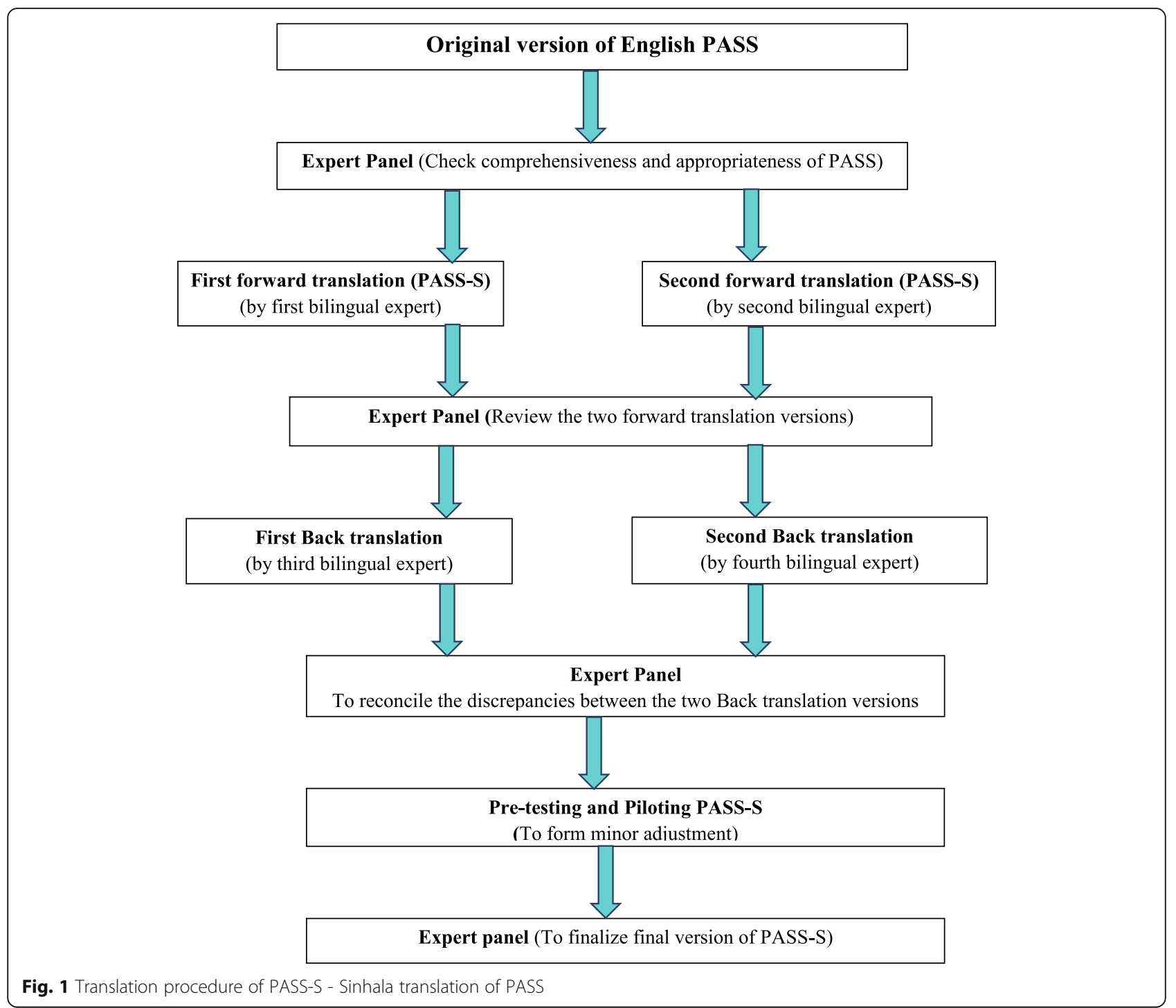

Firstly, the English version of PASS was reviewed by a local expert panel to determine its comprehensiveness and appropriateness for local use. This panel consisted of three psychiatrists, an obstetrician, three community physicians and two clinical psychologists. All 31 items of PASS were marked as suitable for screening anxiety disorders in antenatal women by this expert panel. Secondly, two independent bi-lingual experts translated the PASS into Sinhala. The two Sinhala versions were compared by an expert panel, which included a psychiatrist and three psychologists, and the inadequate terminologies/conceptions of the translation and any discrepancies between two Sinhala translation versions were resolved.

This first draft of the Sinhala version was backtranslated into English by two other independent bilingual translators who were blinded to the English PASS. The back-translation was reviewed by an expert panel, which included a psychiatrist and three psychologists, and 28 items were rated as the correct translation, and the other three items, as needing minor revisions. Discrepancies were discussed and resolved. This panel provided consensual approval on the preservation of original English meaning of all items of PASS.

The standard translation-back translation method that was followed in the study was similar to how the translation of PASS was done in Bangladesh [25] and in Turkey [24].

This Sinhala version was pretested among 20 women 18 years of age or older, attending ANCs of another major tertiary care hospital in Colombo District, which is similar in setting and patients to the CSTH, to assess comprehensibility of the questions. Every fifth woman, as per the clinic registration number, was recruited until 20 women were recruited. They were interviewed by the PI using the probing method in cognitive interviewing approach to confirm the clarity of the questionnaire, 
understanding of the language used and consistency of the answers given.

Upon pre-test, the final Sinhala translation of PASS (PASS-S) was checked by an expert panel comprising three psychiatrists, who were not involved in the initial translation process, for its content, conceptual and semantic validity. The final expert panel confirmed all 31 items of the PASS-S to be of appropriate standard to screen for anxiety symptoms of antenatal women in Sri Lanka, of which 30 items were rated as culturally relevant, and one item, as moderately relevant.

The PASS-S was piloted among 20 women 18 years of age or older, attending primary-care ANCs at community level, to identify any practical constraints in administering this in such clinics where any antenatal screening is likely to take place, including the convenience of administration, participants' problems when responding and any other issues. Those who participated in the pre-test and the pilot study were not included in the actual validation study. Although the sample selected for the pilot test was from different ANCs, they were similar in their characteristics to the sample used for the validation study. All procedures conduced in the main study were piloted except for the clinical interview conducted by the psychiatrist. No practical constraints were encountered and the feasibility of implementation of the validation study was confirmed.

\section{Construct validity of Sinhala translation of PASS}

The construct validity of PASS-S was assessed using the methods described under the section on statistical analysis presented below.

\section{Criterion validity of Sinhala translation of PASS}

Validation of PASS-S against the gold standard was conducted among pregnant women attending ANCs at CSTH.

Recruited women were first assessed by a psychiatrist using ICD-10 criteria. A total of 221 women were recruited including 81 with anxiety disorders. This was immediately followed by administration of the PASS-S as an interviewer administered questionnaire by two trained nurses. The time taken to complete an interview using the PASS-S was 6-8 min on average.

The findings of the psychiatrist and the nurses were blinded to each other. The PASS-S was re-administered to a randomly-selected 20 women $2-3$ days after the initial assessment by the same nurse who administered the PASS-S at the first interview. To another randomlyselected 20 women, the PASS-S was re-administered 23 days after the initial assessment by a nurse different from the one who administered the first interview.

\section{Statistical analysis}

Descriptive data on participants are reported as numbers and percentages or means and standard deviations (SDs). To examine the construct validity of PASS-S, sample adequacy and suitability for factor analysis were conducted using Kaiser-Meyer-Olkin (KMO) test and Bartlett's test, respectively. Principal component analysis (PCA) for factor extraction in exploratory factor analysis (EFA) and oblique rotation method which was suggested for correlated variables [32] were used.

Confirmatory factor analysis (CFA) was also performed after ensuring that the required assumptions were fulfilled. LISREL 10.2 software was used for this. Additivity test was employed to check whether the scale was an additive scale. A four-factor model was evaluated. The indices used to determine the model fit included the absolute fit indices, relative fit indices and parsimony fit indices. Absolute fit indices were chi-squared test, root mean squared error of approximation (RMSEA), goodness of fit index (GFI), adjusted goodness of fit index (AGFI) and standardized root mean squared residual (SRMR). Relative fit indices were comparative fit index (CFI) and non-normed fit index (NNFI), while parsimony fit indices were parsimony goodness of fit index (PGFI) and parsimonious normed fit index (PNFI).

RMSEA values below 0.05 indicate a good fit to data, values between 0.05 and 0.08 , an acceptable fit, values between 0.08 and 0.10, a marginal fit and values above 0.10 , a poor fit [33, 34]. For the CFI and NNFI, values above 0.95 [35] indicate a good fit to data while for GFI and AGFI, over 0.90 indicate a good fit [36].

Using the psychiatrist's diagnosis as the gold standard, the receiver-operating-characteristic (ROC) curve was graphed for the total scores for PASS-S obtained by participants. The optimal cut-off score of the PASS-S for detecting anxiety in pregnancy was determined using Youden's index [37]. Performance of the PASS-S at this optimal cutoff score against the psychiatrist's diagnosis was assessed using sensitivity, specificity and predictive values.

Internal consistency of the PASS-S was measured using Cronbach's alpha. Test-retest reliability and interrater reliability of the total PASS-S scores were assessed using intra-class correlation coefficient (ICC) for the total PASS-S score, and those of anxiety classification (symptomatic of anxiety disorder/ not symptomatic) were assessed using Cohen's kappa (k).

\section{Results}

The mean age \pm SD of the recruited antenatal women was $30 \pm 5.8$ years. Most (74.2\%) of the participants had completed primary education and $56.1 \%$ were multiparous (Table 1). Nearly half (48.9\%) were in the third trimester of pregnancy, while 36.7 and $14.5 \%$ were in the second and first trimesters respectively. 
Table 1 Basic characteristics of the antenatal women $(n=221)$

\begin{tabular}{|c|c|c|}
\hline Variable & Frequency & Percentage (\%) \\
\hline \multicolumn{3}{|l|}{ Age (Years) } \\
\hline $18-23$ & 30 & 13.6 \\
\hline $24-29$ & 80 & 36.2 \\
\hline $30-35$ & 75 & 33.9 \\
\hline $36-41$ & 36 & 16.3 \\
\hline \multicolumn{3}{|l|}{ Level of Education } \\
\hline No schooling & 1 & 0.5 \\
\hline Primary & 164 & 74.2 \\
\hline Secondary & 56 & 25.3 \\
\hline \multicolumn{3}{|c|}{ Monthly income Level (SLR) } \\
\hline $0-20,000$ & 33 & 14.9 \\
\hline $20,001-40,000$ & 118 & 53.4 \\
\hline $40,001-60,000$ & 42 & 19 \\
\hline $60,001-80,000$ & 0 & 0.0 \\
\hline $80,001-100,000$ & 18 & 8.1 \\
\hline 100,001 and above & 10 & 4.5 \\
\hline \multicolumn{3}{|c|}{ Pregnancy and childbirth status } \\
\hline First pregnancy & 97 & 43.9 \\
\hline Living child 1 & 94 & 42.5 \\
\hline Living children 2 & 23 & 10.4 \\
\hline Living Children 3 & 6 & 2.7 \\
\hline Living Children 4 & 0 & 0.0 \\
\hline Living Children 5 & 1 & 0.5 \\
\hline \multicolumn{3}{|c|}{ Trimester in current pregnancy } \\
\hline Trimester1 & 32 & 14.5 \\
\hline Trimester 2 & 31 & 36.6 \\
\hline Trimester 3 & 108 & 48.9 \\
\hline
\end{tabular}

The psychiatrist diagnosed $37.0 \%$ of women $(n=81)$ as having anxiety disorder using ICD-10 Criteria. Most women with anxiety had generalized anxiety disorder or phobias (Table 2).

\section{Criterion validity of PASS-S}

The area under the ROC curve for PASS-S scores was 0.96 (95\% CI: 0.94-0.99) (Fig. 2). The optimal sensitivity and specificity for the PASS-S was found at the score of $\geq 20$. At this cut-off score, the sensitivity was $0.93(95 \%$ CI: 0.84-0.97) and the specificity was 0.90 (95\% CI: $0.83-0.94$ ) (Table 3$)$. The positive and negative predictive values of PASS-S at this cut-off score were 0.85 (95\% CI: 0.75-0.90) and 0.95 (95\% CI: 0.89-0.98) respectively. The positive and negative likelihood ratios were 8.8 (95\% CI: 5.34-14.5) and 0.08 (95\% CI: 0.04-0.18), respectively.

According to PASS-S scores, $3.7 \%$ of the pregnant women $(n=3)$ had severe anxiety symptoms, while
Table 2 Severity and domains of anxiety as assessed by goldstandard (psychiatrist using ICD-10 criteria)

\begin{tabular}{lll}
\hline Severity of anxiety & Frequency & Percentage (\%) \\
\hline Mild & 47 & 58.02 \\
Moderate & 31 & 38.27 \\
Severe & 03 & 3.71 \\
Domains of anxiety & & \\
$\quad$ Generalized anxiety disorder & 30 & 37.03 \\
OCD & 02 & 2.46 \\
Phobias (blood and injection) & 32 & 39.5 \\
Social phobia & 06 & 7.4 \\
Specific fear (Child birth) & 04 & 4.93 \\
PTSD & 01 & 1.23 \\
Panic disorder & 06 & 7.4 \\
\hline
\end{tabular}

96.3\% ( $n=79)$ had mild to moderate anxiety symptoms. Cronbach's alpha for internal consistency was 0.95 (95\% CI: 0.93-0.96). The ICC for total PASS-S score was 0.85 (95\% CI: 0.65-0.96) for test-retest reliability and 0.92 (95\% CI: 0.81-0.97) for inter-rater reliability. The Cohen's kappa for anxiety classification (symptomatic of anxiety disorder/ not symptomatic) was 0.77 (95\% CI: $0.34-1.2)$ for test-retest reliability and 0.86 (95\% CI: 0.59-1.1) for inter-rater reliability.

\section{Construct validity of PASS-S}

The KMO test value for sampling adequacy was 0.95 . Bartlett's test of sphericity was significant $\left(x^{2}=4390.838\right.$; df 496; $p<0.01$ ).

As per the four-factor model analysis, the total variance was $58.1 \%(n=221)$. An examination of the factor loadings after rotation (Table 4) showed that factor 1 ("acute anxiety and adjustment") accounted for $46.9 \%$ of this total variance. Out of the remaining $11.2 \%$ of the total variance, factor 2 ("social anxiety, specific fears and trauma") accounted for $4.0 \%$, factor 3 ("perfectionism and control"), for 3.9\%, and factor 4 ("general anxiety"), for $3.3 \%$. These four factors' factor loading described the characteristics of 31 variables included in the PASS-S.

The results of EFA indicated that four-factor arrangement in PASS-S (with Eigen values over 1 and suppressing absolute value less than .03) explains all the factors included in PASS-S.

\section{Confirmatory factor analysis}

Fit indices obtained in the CFA indicated that the data fit the hypothesized measurement model perfectly. The four-factor model gave a $\chi^{2}$ value of 705.57 (df 428; $p<$ 0.001). RMSEA was 0.056 while SRMR, GFI and AGFI were $0.046,0.83$ and 0.803 respectively. CFI, NNFI, PGFI and PNFI were $0.92,0.919,0.716$ and 0.766 respectively. 


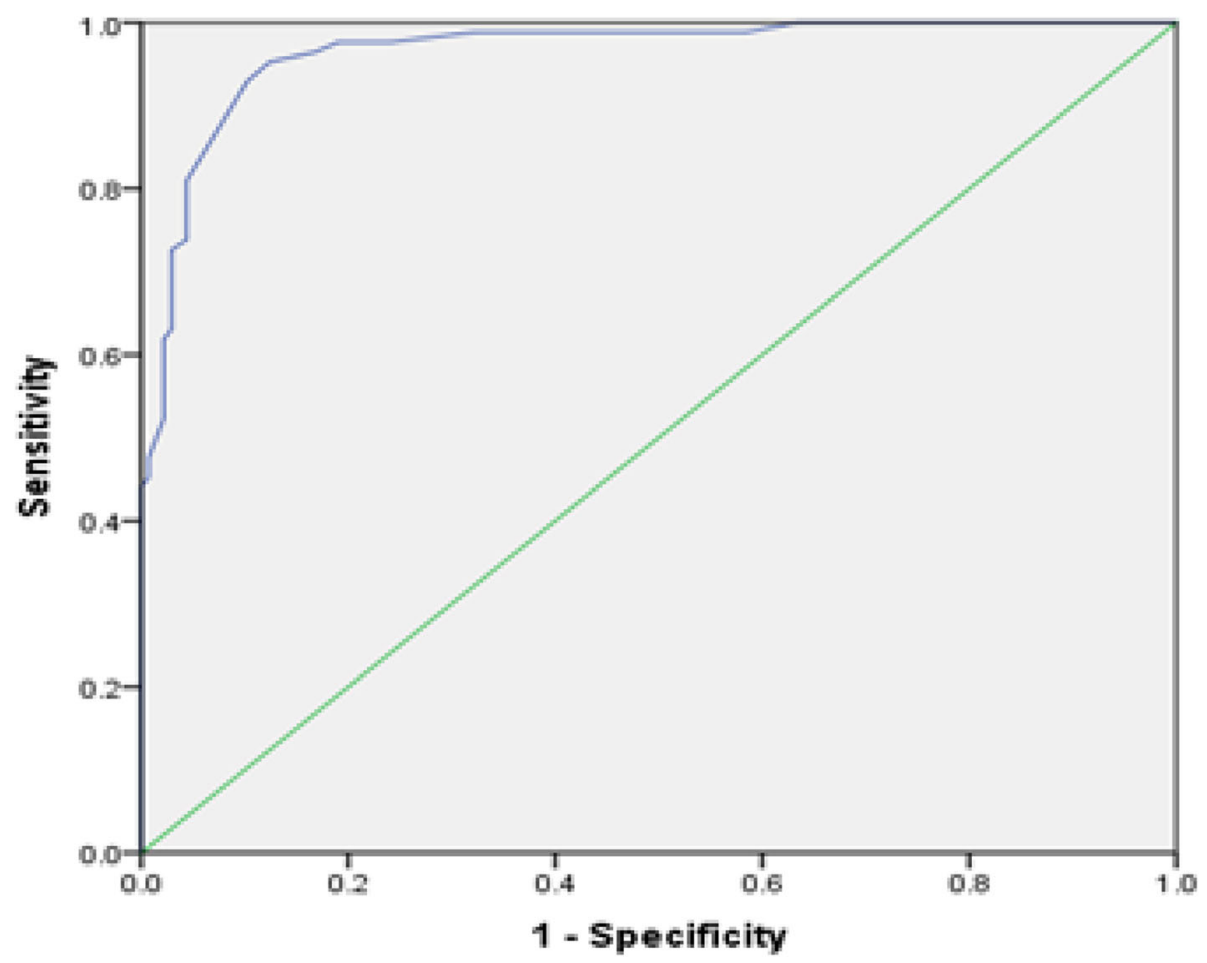

Fig. 2 ROC Curve-The receiver operating characteristic curve of the participants - Area under the curve: 0.96

The four-factor model was closer to the good fit indices in each absolute, relative, and parsimony fit indices.

\section{Discussion}

The Sinhala translation of the PASS has produced a valid and a reliable tool to assess anxiety disorder during

Table 3 Sensitivity and specificity of PASS-S at different cut-off scores (only the scores immediately above and below the optimal cut-off score are shown)

\begin{tabular}{lll}
\hline PASS-S Score & Sensitivity & Specificity \\
\hline 12.50 & .988 & .569 \\
13.50 & .988 & .613 \\
14.50 & .988 & .679 \\
15.50 & .976 & .759 \\
16.50 & .976 & .810 \\
17.50 & .964 & .832 \\
18.50 & .952 & .876 \\
19.50 & .929 & .898 \\
20.50 & .869 & .927 \\
21.50 & .810 & .956 \\
22.50 & .738 & .956 \\
23.50 & .726 & .971 \\
24.50 & .631 & .971 \\
25.50 & .619 & .978 \\
\hline
\end{tabular}

pregnancy in Sri Lanka. The PASS-S showed high sensitivity, specificity, and predictive values in a local clinic setting. Its test-retest and inter-rater reliability measures were also high. It also showed good content, conceptual and semantic validity similar to those in the two studies conducted in Turkey [24] and Bangladesh [25], indicating appropriateness of the PASS for use in multicultural settings.

Sampling adequacy for EFA was excellent $(\mathrm{KMO}=$ 0.95) and was similar to the English PASS validation study $(\mathrm{KMO}=0.96)[22]$. Inter-item correlation was sufficiently large for PCA (Bartlett's test of sphericity, $p<$ 0.00 ), and was also similar to that of the English PASS. Although the number of factors identified was 4 in the English PASS, the item distribution for the factors slightly varied from the English PASS and PASS-TR. In the English PASS, factor 1 (acute anxiety and adjustment) had items that addressed symptoms of panic disorder, dissociative disorder and adjustment difficulties, factor 2 (general worry and specific fears) covered symptoms of general anxiety disorder and phobia, factor 3 (perfectionism, control and trauma) included symptoms of obsessive compulsive disorder and post-traumatic stress disorder, and factor 4 (social anxiety) had questions to determine social anxiety. However, in the PASS$\mathrm{S}$, factor direction and the titles of factors were altered. Factors 1-4 were reclassified as "acute anxiety and adjustment" covering symptoms of panic disorders, acute 
Table 4 Factor Structure of PASS-S

\begin{tabular}{|c|c|c|c|c|}
\hline \multirow[t]{2}{*}{ Factors } & \multicolumn{4}{|c|}{ Factor } \\
\hline & 1 & 2 & 3 & 4 \\
\hline \multicolumn{5}{|l|}{ 1. "Acute anxiety and adjustment" } \\
\hline 25. Losing track of time and can't remember what happened & .775 & & & \\
\hline 27. Anxiety getting in the way of being able to do things & .754 & & & \\
\hline 29. Fear of losing control & .751 & & & \\
\hline 30. Feeling panicky & .744 & & & \\
\hline 28. Racing thoughts making it hard to concentrate & .688 & & & \\
\hline 26. Difficulty adjusting to recent changes & .684 & & & \\
\hline 23. Avoiding things which concern me & .658 & & & \\
\hline 24. Feeling detached like you're watching yourself in a movie & .632 & & & \\
\hline 21. Feeling really uneasy in crowds & .543 & & & \\
\hline 22. Avoiding social activities because I might be nervous & .440 & & & \\
\hline 7. Really strong fears about things, eg needles, blood, birth, pain, etc & .428 & & & \\
\hline 31. Feeling agitated & .413 & &.-367 & \\
\hline \multicolumn{5}{|l|}{ 2. "Social anxiety, specific fears and trauma" } \\
\hline 19. Worry that I will embarrass myself in front of others & & .719 & & \\
\hline 1. Worry about the baby/pregnancy & & .611 & & \\
\hline 4. Worry about many things & & .602 & & \\
\hline 20. Fear that others will judge me negatively & & .487 & & \\
\hline 5. Worry about the future & & .407 & & .301 \\
\hline 18. Upset about repeated memories, dreams or nightmares & & .421 & & \\
\hline 3. A sense of dread that something bad is going to happen & .334 & .364 & & \\
\hline 17. Being 'on guard' or needing to watch out for things & .301 & .319 & & \\
\hline \multicolumn{5}{|l|}{ 3. "Perfectionism \&control" } \\
\hline 11. Having to do things in a certain way or order & & & -.587 & \\
\hline 12. Wanting things to be perfect & .324 & & -.560 & \\
\hline 13. Needing to be in control of things & & & -.703 & \\
\hline 14. Difficulty stopping checking or doing things over and over & & & -.645 & \\
\hline 15. Feeling jumpy or easily startled & & & -.596 & \\
\hline 16. Concerns about repeated thoughts & & & -.646 & \\
\hline \multicolumn{5}{|l|}{ 4. "General anxiety" } \\
\hline 6. Feeling overwhelmed & & & & .726 \\
\hline 10. Difficulty sleeping even when I have the chance to sleep & & & & .534 \\
\hline 2. Fear that harm will come to the baby & & & -.336 & .509 \\
\hline 9. Repetitive thoughts that are difficult to stop or control & & & & .399 \\
\hline 8. Sudden rushes of extreme fear or discomfort & & & & .465 \\
\hline
\end{tabular}

stress and adjustment disorders, "social anxiety, specific fears and trauma" covering symptoms of social anxiety disorder, phobias and post-traumatic stress disorder; "perfectionism and control" covering symptoms of obsessive compulsive disorder and "general anxiety" covering symptoms of generalized anxiety disorder, respectively. These changes were essential components of intercultural adaptation, and the factor structure of the current study reflects specific classification of anxiety disorder in the Sri Lankan context. The factor analysis showed that generalized and acute anxiety symptoms are more prominent (factors loaded under factor 1 of the factor structure) among antenatal women in Sri Lanka while excessive worry and specific fears were prominent anxieties among participants of the English PASS validation study [22].

The optimal cut-off point of $\geq 20$ for PASS-S was lower than the score of 26 for the English PASS [22] but 
higher than the score of 16 for the PASS-TR [24]. It suggests that Sri Lankan women's risk for anxiety disorders occurs at a lower symptoms threshold compared with their Australian counterparts but at a higher threshold compared with Turkish women [24]. The specificity of the PASS-S was similar to that of the PASS-TR but higher than that of the English PASS while the sensitivity of the PASS-S was higher than those of both the English PASS [22] and the PASS-TR [24]. One reason for comparable sensitivity with the PASS-TR may be due to assessment of criterion validity in both these studies against the gold standard and using the entire sample. In the English validation study, criterion validity was assessed only in a sub-sample. The socio-cultural factors that differentially affect participants from different geographical areas may also have contributed to the variable perception and reporting of anxiety symptoms by participants in different studies. The Bangladesh study did not report sensitivity, specificity or cut-off scores since criterion validity was not assessed [25]. When a screening tool has high sensitivity and high specificity, it detects large proportions of true positives and true negatives, and its quality is at an optimum level [38]. Furthermore, the accuracy of a screening test depends on its ability to differentiate between those who have and who do not have the disease and is measured by the area under the ROC curve. The PASS-S accurately classified $96 \%$ of women with and without anxiety disorder compared to $93 \%$ for the PASSTR [24] and 70\% for the English PASS [22]. The minimal misclassification that occurred when PASS-S was used makes it an ideal tool to be used in settings where the gold standard assessment is not feasible.

The internal consistency of the PASS-S was similar to the Turkish PASS [24], the Bangla PASS [25] and the English PASS [22]. The high test-retest ICC for the total score (0.85) and Cohen's kappa (0.77) for anxiety disorder classification indicates that the symptoms measured in the PASS-S were stable over time. A high test-retest reliability for the total score was also seen in the English PASS (Pearson $r=0.74$ [22]) and the Bangla PASS (Pearson $r=$ 0.83 [25]). Our study is the first to report inter-interviewer reliability for the PASS in any language and showed that this was high for the total score (ICC 0.92) and anxiety disorder classification (Cohen's kappa 0.86). This suggests that the PASS-S is suitable for use in clinic settings that often have multiple interviewers.

The PASS-S was administered as an intervieweradministered questionnaire to maximize the response rate and to ensure that literacy level of the participants did not influence the responses $[39,40]$. The time taken to complete it was 6-8 $\mathrm{min}$ on average. This was not very different from the time taken to complete the English PASS and the PASS-TR (2-10 min), which were self-administered questionnaires [22, 24].
The main strength of our study is that the PASS-S was validated against the gold standard of a psychiatric diagnosis of anxiety disorders. Ours is only the second study to do this, the first being validation of the PASS-TR against both Diagnostic and Statistical Manual of Mental Disorders-4th edition (DSM-IV) criteria and ICD-10 criteria [24]. Furthermore, the performance of the PASS-S compared well with the English PASS and its other translated versions for validity, reliability and discriminatory ability. One limitation in our study is that our sample represented mostly the urban and semi-urban antenatal women in Sri Lanka. Although nearly half of the Sri Lankan women belong to this category [41], rural women might perceive and express symptoms of anxiety disorders differently [42]. In this context, the PASS-S may need further validation before using it to screen antenatal women of a rural population.

The good validity and reliability of the PASS-S make it a suitable tool to be used in clinical practice and in research, and may even be used routinely to screen for anxiety disorders among antenatal women in Sri Lanka. Further studies to assess the feasibility of using the PASS-S as a screening tool to detect anxiety disorders during routine antenatal care are recommended. Validation of the PASS in Tamil, the other local language in Sri Lanka, is also recommended.

\section{Conclusion}

The PASS-S is a valid and reliable instrument to assess anxiety during pregnancy among Sinhala speaking women, and may be useful in routine assessment of anxiety in such women.

\section{Supplementary information}

Supplementary information accompanies this paper at https://doi.org/10. 1186/s12888-020-02757-Z

Additional file 1: Table S1. Result of content/consensual validityAppropriateness of factor structure use in Sri Lankan context. Table S2. Comparison of Factor Structure in PASS and PASS-S. Table S3. Fit indices, their description and cut-off values used for interpreting model fit in CFA (1).

\footnotetext{
Abbreviations

PASS: Perinatal Anxiety Screening Scale; PASS-S: Sinhala version of Perinatal Anxiety Screening Scale; STAl: State-Trait Anxiety Inventory; GAD7: Generalized Anxiety Disorder 7-item; EPDS: Edinburgh Postnatal Depression Scale; PASS-TR: Turkish translation of Perinatal Anxiety Screening Scale; WHO: World Health Organization; ROC: Receiver-operatingcharacteristic; PI: Principal Investigator; ERC: Ethics Review Committee; k: Cohen kappa; ICC: Intra-class correlation coefficient; EFA: Exploratory factor analysis; PCA: Principal component analysis; CFA: Confirmatory factor analysis; ANC: Antenatal clinics; ICD-10: International Classification of Diseases-10; RMSEA: Root mean square error of approximation; RMR: Root mean square Residual; GFI: Goodness of fit index; AGFI: Adjusted goodness-of-fit index; CFI: Comparative fit index; KMO: Kaiser-Meyer-Olkin; DSM-IV: Diagnostic and Statistical Manual of Mental Disorders, 4th edition
} 


\section{Acknowledgements}

We thank Susanne Somerville for granting permission to translate and validate PASS into Sinhala language. The health staff who assisted in translation and validation process and participants of this study are also acknowledged. We thank Dr. A. Wijayasiri and Dr. S. Jayakody for their contribution in the statistical analysis. We also acknowledge the Research Council of University of Sri Jayewardenepura for funding the study.

\section{Authors' contributions}

MNP collected and analyzed data, interpreted results and was responsible for manuscript writing. MDIAW contributed to data acquisition by conducting the diagnostic clinical interviews as per the International Classification of Diseases-10 criteria (ICD-10) and to writing the discussion. DMSF and BCVS as senior authors contributed by conceptualizing and developing the study, interpreting results and in revising the manuscript. CSEG contributed to implementing the study and revising the manuscript. $A B$ contributed to interpreting results. All authors read and approved the final version of the manuscript. All authors are guarantors of the paper.

\section{Funding}

Data collection was funded by University of Sri Jayewardenepura Research Grants (ASP/RE/MED/17/39). The rest of the data collection, data entry, data analysis and publication were done through voluntary contributions.

\section{Availability of data and materials}

The datasets used and/or analyzed (those including personal information of antenatal women) during the current study are available from the corresponding author on reasonable request.

\section{Ethics approval and consent to participate}

Ethical approval was obtained from the Ethics Review Committee (ERC ref. No: 25/ 27th May 2017) of the Faculty of Medical Sciences, University of Sri Jayewardenepura, Sri Lanka. All participants were informed that their participation was voluntary and their identities would be kept strictly confidential. Informed written consent was taken from all participants who voluntarily participated.

\section{Consent for publication}

Not applicable.

\section{Competing interests}

The authors declare that they have no competing interests.

\section{Author details}

'Department of Nursing \& Midwifery, Faculty of Allied Health Sciences, Kotelawala Defence University, Rathmalana, Sri Lanka. ${ }^{2}$ Department of Psychiatry, Faculty of Medical Sciences, University of Sri Jayewardenepura, Nugegoda, Sri Lanka. ${ }^{3}$ Department of Community Medicine, Faculty of Medical Sciences, University of Sri Jayewardenepura, Nugegoda, Sri Lanka. ${ }^{4}$ Department of Public Health, Faculty of Medicine, Kotelawala Defence University, Rathmalana, Sri Lanka. ${ }^{5}$ Non-Communicable Diseases Research Centre, University of Sri Jayewardenepura, Nugegoda, Sri Lanka. ${ }^{6}$ Department of Physiology, Faculty of Medical Sciences, University of Sri Jayewardenepura, Nugegoda, Sri Lanka.

Received: 29 December 2019 Accepted: 23 June 2020

\section{Published online: 21 July 2020}

\section{References}

1. Ross LE, McLean LM. Anxiety disorders during pregnancy and the postpartum period: a systematic review. J Clin Psychiatry. 2006;67(8): 1285-98.

2. Ross LE, Gilbert Evans SE, Sellers EM, Romach MK. Measurement issues in postpartum depression part 1: anxiety as a feature of postpartum depression. Arch Womens Ment Health. 2003;6(1):51-7.

3. Anniverno R, Bramante A, Mencacci C, Durbano F. Anxiety disorders in pregnancy and the postpartum period. New Insights Anxiety Disord. 2013; Available from: https://www.intechopen.com/books/new-insights-intoanxiety-disorders/anxiety-disorders-in-pregnancy-and-the-postpartumperiod. Cited 2020 Apr 15.
4. Rubinchik SM, Kablinger AS, Gardner JS. Medications for panic disorder and generalized anxiety disorder during pregnancy. Prim Care Companion J Clin Psychiatry. 2005;7(3):100-5.

5. Guardino CM, Schetter CD. Understanding pregnancy anxiety; 2014. p. 10.

6. Leach LS, Poyser C, Fairweather-Schmidt K. Maternal perinatal anxiety: a review of prevalence and correlates. Clin Psychol. 1(21):4-19.

7. Dennis C-L, Falah-Hassani K, Shiri R. Prevalence of antenatal and postnatal anxiety: systematic review and meta-analysis. Br J Psychiatry. 2017;210(5):315-23.

8. Shahhosseini Z, Pourasghar M, Khalilian A, Salehi F. A review of the effects of anxiety during pregnancy on children's health. Mater Sociomed. 2015; 27(3):200.

9. Roomruangwong C, Epperson CN. Perinatal depression in Asian women: prevalence, associated factors, and cultural aspects. Asian Biomed. 2011;5(2): 179-93.

10. Agampodi SB, Agampodi TC. Antenatal depression in Anuradhapura, Sri Lanka and the factor structure of the Sinhalese version of Edinburgh post partum depression scale among pregnant women. Coyne J, editor. PLoS One. 2013;8(7):e69708.

11. Agampodi T, Agampodi S, Wickramasinghe W, Adhikari A, Chathurani H. Post partum depression - a problem that needs urgent attention. Ceylon Med J. 2011;56(4):183.

12. Rauchfuss M, Maier B. Biopsychosocial predictors of preterm delivery. J Perinat Med. 2011;39(5):515-21.

13. Dunkel Schetter C. Psychological science on pregnancy: stress processes, biopsychosocial models, and emerging research issues. Annu Rev Psychol. 2011;62:531-58

14. Dunkel Schetter C, Glynn L. Stress in pregnancy: empirical evidence and theoretical issues to guide interdisciplinary researchers. In: Contrada R, Baum A, editors. Handbook of stress science: biology, psychology, and health. New York: Springer Publishing Company; 2011. p. 321-43.

15. Ding X-X, Wu Y-L, Xu S-J, Zhu R-P, Jia X-M, Zhang S-F, et al. Maternal anxiety during pregnancy and adverse birth outcomes: a systematic review and metaanalysis of prospective cohort studies. J Affect Disord. 2014;159:103-10.

16. Madhavanprabhakaran GK, D'Souza MS, Nairy KS. Prevalence of pregnancy anxiety and associated factors. Int J Afr Nurs Sci. 2015;3:1-7.

17. Fairbrother $\mathrm{N}$, Young AH, Janssen $\mathrm{P}$, Antony MM, Tucker E. Depression and anxiety during the perinatal period. BMC Psychiatry. 2015;15:206.

18. Spielberger CD, Gorsuch RL, Lushene RE. Manual for the State-Trait Anxiety Inventory. 1970. Available from: http://ubir.buffalo.edu/xmlui/handle/104 77/2895. Cited 2020 Apr 19.

19. Spitzer RL, Kroenke K, Williams JBW, Löwe B. A brief measure for assessing generalized anxiety disorder: the GAD-7. Arch Intern Med. 2006;166(10): 1092-7.

20. Van den Bergh BRH. The influence of maternal emotions during pregnancy on fetal and neonatal behavior. J Prenat Perinat Psychol Health. 1990;5(2):119-30.

21. Levin JS. The factor structure of the pregnancy anxiety scale. J Health Soc Behav. 1991;32(4):368-81.

22. Somerville S, Dedman $K$, Hagan $R$, Oxnam E, Wettinger M, Byrne $S$, et al. The perinatal anxiety screening scale: development and preliminary validation Arch Womens Ment Health. 2014;17(5):443-54.

23. Somerville S, Byrne SL, Dedman K, Hagan R, Coo S, Oxnam E, et al. Detecting the severity of perinatal anxiety with the perinatal anxiety screening scale (PASS). J Affect Disord. 2015;186:18-25.

24. Yazııı E, Mutu Pek T, Uslu Yuvacı H, Köse E, Cevrioglu S, Yazıcı AB, et al. Perinatal anxiety screening scale validiy and reliability study in Turkish (PASS-TR validity and reliability). Psychiatry Clin Psychopharmacol. 2019; 29(4):609-17.

25. Yasmin, Islam. Adaptation of the perinatal anxiety screening scale in Bangladeshi context. Psychol Psychol Res Int J. 2018;3(1):000144.

26. Pereira AT, Pinto C, Azevedo J, Marques C, Xavier S, et al. Validity and reliability of the perinatal anxiety screening scale in a portuguese sample of pregnant women. 27th European Congress of Psychiatry. 2019.

27. Murray D, Cox JL. Screening for depression during pregnancy with the Edinburgh depression scale (EDDS). J Reprod Infant Psychol. 1990;8(2):99-107.

28. Faculty of Medical Sciences - Teaching Hospital. Available from: http:// medical.sjp.ac.lk/index.php/electives-teaching-hospital. Cited 2020 Apr 15.

29. Colombo South Teaching Hospital | Colombo, Sri Lanka | [Internet]. ResearchGate. Available from: https:/www.researchgate.net/institution/ Colombo_South_Teaching_Hospital. Cited 2020 Apr 15.

30. WHO. International statistical classification of diseases-10. 10th ed. Geneva: WHO Press; 2010. 
31. Harkness J, Pennell BE, Villar A, Gebler N, Aguilar-Gaxiola S, Bilgen I. Translation procedures and translation assessment in the world mental health survey initiative. In: The who world mental health survey: global perspectives on the epidemiology of mental disorders. Geneva: World Health Organization, Cambridge University Press; 2008. p. 91-113.

32. Field A. Discovering statistics using SPSS. 3rd ed. London: SAGE Publications Ltd; 2009. p. 857.

33. Fabrigar $L R$, Wegener DT, MacCallum RC, Strahan EJ. Evaluating the use of exploratory factor analysis in psychological research. Psychol Methods. 1999; 4(3):272-99. https://doi.org/10.1037/1082-989X.4.3.272.

34. Hwang KS, Jang SH, Lee HJ, Lee SY. Reliability and validity of the Korean version of health anxiety questionnaire. Psychiatry Investig. 2018;10(15):976-83.

35. Mulaik SA, James LR, Van Alstine J, Bennett N, Lind S, Stilwell CD. Evaluation of goodness-of-fit indices for structural equation models. Psychol Bull. 1989; 3(105):430-45.

36. Jöreskog KG, Sörbom D. LISREL 8: user's reference guide. 2. Ed., updated to LISREL 8. Lincolnwood: Scientific Software International; 2001. p. 378.

37. Zou KH, Hall WJ, Shapiro DE. Smooth non-parametric receiver operating characteristic (ROC) curves for continuous diagnostic tests. Stat Med. 1997; 16(19):2143-56.

38. Lalkhen AG, McCluskey A. Clinical tests: sensitivity and specificity. Contin Educ Anaesth Crit Care Pain. 2008:8(6):221-3.

39. Tsakos G, Bernabé E, O'Brien K, Sheiham A, de Oliveira C. Comparison of the self-administered and interviewer-administered modes of the child-OIDP. Health Qual Life Outcomes. 2008;6:40.

40. Guyatt GH, Feeny DH, Patrick DL. Measuring health-related quality of life. Ann Intern Med. 1993;118(8):622-9.

41. Department of Census and Statistics. Household income and expenditure survey; 2016. p. 176

42. Khambaty M, Parikh RM. Cultural aspects of anxiety disorders in India. Clin Res. 2017;19(2):10.

\section{Publisher's Note}

Springer Nature remains neutral with regard to jurisdictional claims in published maps and institutional affiliations.

Ready to submit your research? Choose BMC and benefit from:

- fast, convenient online submission

- thorough peer review by experienced researchers in your field

- rapid publication on acceptance

- support for research data, including large and complex data types

- gold Open Access which fosters wider collaboration and increased citations

- maximum visibility for your research: over $100 \mathrm{M}$ website views per year

At $\mathrm{BMC}$, research is always in progress.

Learn more biomedcentral.com/submissions 